\title{
The Trend of Device-Associated Hospital Acquired Infections in an Adult Intensive Care Unit of a Tertiary Care Hospital: A Need to Revamp Preventive Strategies
}

\author{
Bineeta Kashyap $^{1 *}$, Rajat Jhamb² ${ }^{2}$ Rituparna Saha1 ${ }^{\circledR}$, Pratima Prasad $^{3}$ \\ 'Department of Microbiology, University College of Medical Sciences \& Guru Teg Bahadur Hospital, Delhi, India \\ 2Department of Medicine, University College of Medical Sciences \& Guru Teg Bahadur Hospital, Delhi, India \\ ${ }^{3}$ Hospital Infection Control Committee, Guru Teg Bahadur Hospital, Delhi, India
}

*Corresponding Author: Bineeta Kashyap, M.D., Associate Professor, Infection Control Officer, Department of Microbiology, University College of Medical Sciences \& Guru Teg Bahadur Hospital, Delhi, India. Tel: +91-9899583514, Email: dr_bineetakashyap@yahoo.co.in

Received March 26, 2021; Accepted June 1, 2021; Online Published August 11, 2021

\begin{abstract}
Background: Device-associated infections (DAIs) like ventilator-associated pneumonia (VAP), central-line-associated blood stream infections (CLABSI), and catheter-related urinary tract Infection (CAUTI) constitute predominant healthcare-associated infections (HAls) in intensive care units (ICUs).

Objectives: The study aims to elucidate their trends in an adult ICU.

Methods: Over 21 months, monthly VAP, CLABSI, and CAUTI rate, and device utilization ratios were calculated in an adult ICU of a tertiary care hospital as part of routine surveillance activity. All cases of VAP, CLABSI, and CAUTI during these 21 months were included. In addition, monthly hand hygiene compliance rates were assessed during the latter period of the study by direct observation method.

Results: Nosocomial DAI rate was 49.38 DAI/1000 ICU days. CAUTI, CLABSI, and VAP rates were 17.38, 26.85, 21.08 per 1000 device days, and device utilization ratios were $0.99,0.61$, and 0.02 , respectively.

Conclusion: The institute had high DAI rates in comparison to other studies from the same city. The declining trend of CAUTI rates roughly coincided with surveillance for hand hygiene compliance in ICU. Thus, it establishes baseline data and underscores the need for focused HIC to maximize patient outcomes.

Keywords: Infection Control, Intensive Care Unit, Policy
\end{abstract}

\section{Background}

The last few decades have witnessed enormous strides in the medical field in diagnostics, therapeutics, and palliation. Advances in technologies have revolutionized critical care and reduced adverse outcomes significantly. However, the increasing popularity of established and newer medical devices in health care has emanated the menace of device-associated infections (DAI), especially in intensive care units (ICUs). DAIs constitute a sizable burden of healthcare-associated infections (HAIs) in ICU, resulting in accruing costs, duration of hospitalization, morbidity, and mortality. ${ }^{1}$ HAI has been conventionally defined as infections acquired after 48 hours of admission, which were not evident or under incubation at the time of admission. According to studies, 95\% of cases of urinary tract infections in critically ill patients are catheter-related, $87 \%$ of cases of bloodstream infections tend to bud from an indwelling vascular catheter, and mechanical ventilation contributes to 86 percent of cases of pneumonia. ${ }^{2}$

The widely prevalent DAIs in ICU settings that is; ventilator-associated pneumonia (VAP), central-lineassociated blood stream infections (CLABSIs), and catheter-related urinary tract infection (CAUTI), are principal contributors to healthcare-generated preventable hazards for patients. Additionally, ICU environments' ubiquitous multidrug-resistant organisms (MDROs) increase the complexity of managing DAIs, often caused by these MDROs. Thus, "The National Patient Safety Goals" devised by WHO in 2009 has asserted upon the mandatory and targeted formulation of institutional policies for

Copyright (C) 2021 The Author(s). This is an open-access article distributed under the terms of the Creative Commons Attribution License (http:// creativecommons.org/licenses/by/4.0), which permits unrestricted use, distribution, and reproduction in any medium, provided the original work is properly cited. 
surveillance and collaborative approach for the control of DA-HAI in hospitals.

Though an age-old concept, antimicrobial stewardship could be a boon to curb HAI rates and reduce health care costs, mortality, and morbidity. ${ }^{3}$ The radical concept of "diagnostic stewardship" has a potentially vital role to play in HAI surveillance. ${ }^{4}$ Erroneous diagnosis of HAI can result in increased costs, harm the patient, and cumulate to yield faulty infection control indices. Studies also suggest that stewardship programs are most effective when they are coupled with infection prevention strategies. ${ }^{3}$ Thus stewardship programs are increasingly being advocated for accreditation for hospitals as well. Nevertheless, irrespective of the available infrastructure and implementation of the above policies, the adherence to available and standard infection control measures are irreplaceable. Awareness and compliance to as simple a measure as hand hygiene could drastically alter the HAI indices. However, the attitude, surveillance, and documentation of such infection control practices are essential to render comparability and formulation of policies.

\section{Objectives}

The study aims to elucidate their trends in an adult ICU tertiary care hospital. In addition, an attempt has also been made to ascertain the plausible impact of reinforcing hand hygiene measures by mere observation of $\mathrm{HH}$ practices and their resultant impact on HAI rates in the latter part of the study.

\section{Methods}

The study is a cross-sectional study conducted at the University College of Medical Sciences and Guru Teg Bahadur Hospital. This 1700 bedded hospital caters to a substantial inflow of patients from eastern Delhi and the adjoining areas of neighboring states. Among the various ICUs under the aegis of the hospital, we have undertaken the study to ascertain the baseline prevalent DAI indices in the main ICU.

For the surveillance of DAI in the main adult ICU, daily data were collected prospectively over 21 months. A dedicated HICN was involved in the daily monitoring of the eight bedded main ICU and recording data on specifically designed surveillance forms. Monthly DAI were viz. CAUTI, CLABSI, and VAP were defined as per CDC's case definitions. ${ }^{5}$ VAP was defined as new or progressive infiltrates, consolidation, cavitation, or pleural effusion on chest radiographs in a mechanically ventilated patient who has at least one of the following: New-onset purulent sputum or change in the character of sputum; positive blood culture; or isolation of the pathogen from tracheal aspirate, bronchial brushings, broncho-alveolar lavage or lung biopsy. CAUTI was defined as urinary tract infection occurring while an in-situ indwelling urinary catheter was present $>2$ calendar days on the event, considering the day of catheter placement as day one and the indwelling catheter was in-situ on the day of the event or the day before. A CLABSI case has been defined as laboratory-confirmed bloodstream infection in patients with an in-situ central venous catheter. From whom a conventional pathogen being isolated upon blood culture from one or more percutaneous samples after 48 hours of catheterization, which is unrelated to infection in any other site and has one of the following: fever, chills, or hypotension. All cases of VAP, CLABSI, and CAUTI in the adult ICU during the 21 months of study were included.

For convenience and comparability sake, the entire study duration has been sectionalized into three distinct periods of 7 months each. The period I spanned from April 2018 to October 2018; Period II comprised months between November 2018 and May 2019 and Period III covered June 2019 to December 2019. Patient days were calculated daily and expressed cumulatively at the end of each month. All DAI rates were expressed per 1000 device days, and the device utilization ratios were calculated by dividing the number of device days by patient days.

The study period has been sectioned into three periods for comparability and convenience, and the parameters studied accordingly. Period I encompasses April 2018 to October 2018; Period II spans from November 2018 to May 2019 and Period III from June 2019 to December 2019.

\subsection{Monitoring Compliance to Hand Hygiene}

Hand hygiene compliance was calculated every month with the help of a predesigned proforma and manual observation for 30 minutes on consecutive 15 days of a month. The proforma for monitoring hand hygiene was formulated based on the WHO's five moments of hand hygiene.

\section{Results}

During the study period of 21 months, over 800 patients were admitted to the eight bedded main ICU of the hospital. It subsequently amounted to 5446 patient days, followed up daily for DAIs as a component of HIC surveillance. The overall rates of CAUTI, CLABSI, and VAP were 17.38, 26.85 , and 21.08 per thousand patient days, respectively, while the device utilization ratios like urinary catheter utilization ratio, central line utilization ratio, and ventilator utilization ratio were $0.99,0.61$, and 0.02 respectively. The overall nosocomial DAI rate was 49.38 DAI per 1000 ICU days. Figure 1 depicts the proportion of various DAIs in the main ICU.

The sectional measurement indices for DAI in the main ICU are depicted in Table 1.

\subsection{Catheter-Associated UTI}

Among all the patients admitted to the main ICU, there were 5352 catheter-days over 21 months, resulting in 93 CAUTI cases. Figure 2 depicts a comparison between the CAUTI rates and catheter utilization rates ratio in the 
Device-associated infections

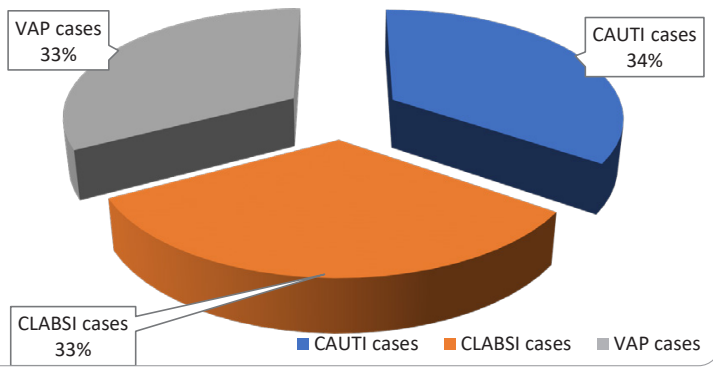

Figure 1. Percentages of the Various Device-Associated Infections in the Main ICU.

Table 1. Period wise device associated infection indices

\begin{tabular}{lccc}
\hline & $\begin{array}{c}\text { Period I } \\
\text { April } \\
\text { 2018-October } \\
\mathbf{2 0 1 8}\end{array}$ & $\begin{array}{c}\text { Period II } \\
\text { November } \\
\mathbf{2 0 1 8 - M a y} \\
\mathbf{2 0 1 9}\end{array}$ & $\begin{array}{c}\text { Period III } \\
\text { June 2019- } \\
\text { December } \\
\mathbf{2 0 1 9}\end{array}$ \\
\hline Urinary catheter days & 1846 & 1792 & 1714 \\
\hline Central line days & 922 & 1099 & 1257 \\
$\begin{array}{l}\text { Ventilator days } \\
\text { Patient days }\end{array}$ & 1492 & 1351 & 1333 \\
$\begin{array}{l}\text { CAUTI rate (\%) } \\
\text { CLABSI rate (\%) }\end{array}$ & 1877 & 1822 & 1747 \\
$\begin{array}{l}\text { VAP rate (\%) } \\
\text { The urinary catheter } \\
\text { utilization ratio }\end{array}$ & 14.63 & 18.42 & 19.26 \\
\hline $\begin{array}{l}\text { Central line } \\
\text { utilization ratio }\end{array}$ & 0.99 & 36.4 & 19.89 \\
\hline $\begin{array}{l}\text { Ventilator utilization } \\
\text { ratio }\end{array}$ & 0.5 & 17.77 & 30.76 \\
\hline
\end{tabular}

different time sections.

\subsection{Central Line-Associated Bloodstream Infection}

There was a total of 3278 central line days over 21 months resulting in 88 CLABSI cases. Figures 3 and 4 depict a comparison between the annual CLABSI rates and central line utilization rates ratio.

\subsection{Ventilator-Associated Pneumonia}

For 4176 ventilator days during the entire study period of 21 months, 88 VAP cases were registered. Figure 3 and Figure 4 depict a comparison between the annual VAP rates and ventilator utilization rates ratio.

The comparative illustration of the DAI trend over the entire study duration of 21 months is given in Figure 4 and Table 2. In addition, the hand hygiene compliance rates from September 2019 to December 2019 are depicted in Table 3.

\section{Discussion}

Targeted surveillance of DAIs in ICUs forms the cornerstone of hospital infection control and prevention programs. The DAI rates serve as the linchpin for the various facets

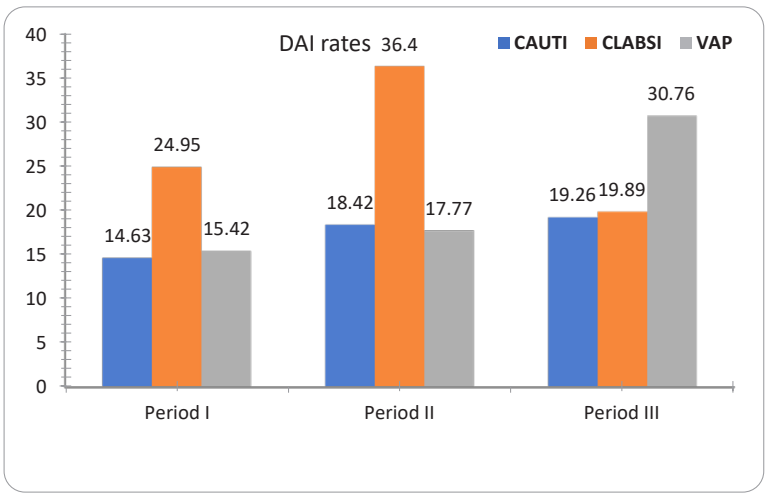

Figure 2. Comparison of CAUTI, CLABSI, and VAP Rates.

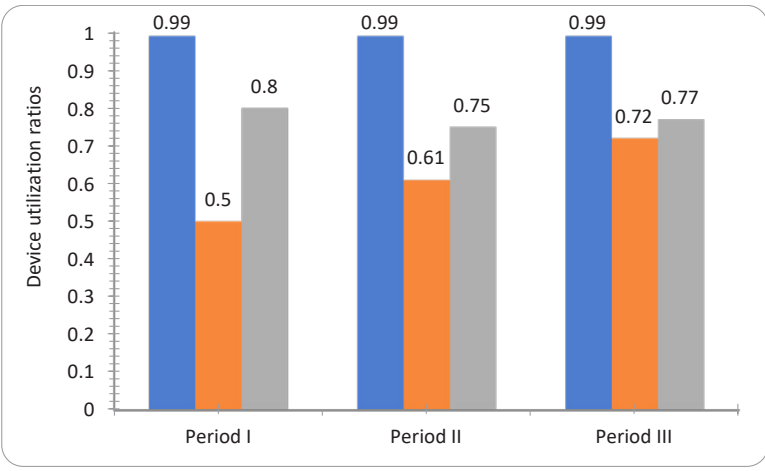

Figure 3. Comparison of Devise Utilization Ratios.

of hospital infection control and further help shape prevention strategies, apart from rendering comparability among institutions. ${ }^{6}$ HAI rates have been known to vary from $5 \%-10 \%$ in the developed nations, but substantially higher DAI rates surmounting $40 \%$ are reported from the developing world. ${ }^{7-10}$ Despite the availability of evidence-based surveillance guidelines widely accepted in industrialized nations, countries with resourcelimited conditions have suboptimal implementation and surveillance systems to abate hospital-acquired DAIs. ${ }^{11,12}$ Additionally, the lack of uniformity in implementing such surveillance tools intensifies the vacuum of data from the developing countries. ${ }^{13}$ The present study attempts to bridge the chasm of deficient baseline data about prevalent DAIs within the institute, which would serve as an impetus to strengthen and expedite infection control endeavors.

The most common hospital-acquired DAI in the main ICU was VAP accounting for 34\% of 269 DAI cases, while rates of CAUTI and CLABSI were comparable (33\%). The overall DAI rate in the study (49.38) was much higher than similar studies from another city region, reporting 21.6 DAI/1000 ICU days. ${ }^{14}$ However, similar rates of VAP have been documented by Singh et al in their study conducted in a different province of India (21.92 per 1000 ventilator days) and the pooled International Nosocomial Infection Control Consortium (INICC) data from Brazilian hospitals. ${ }^{15,16}$ Resonating with our findings, a study conducted in Iran has also reported a 21.08 per 


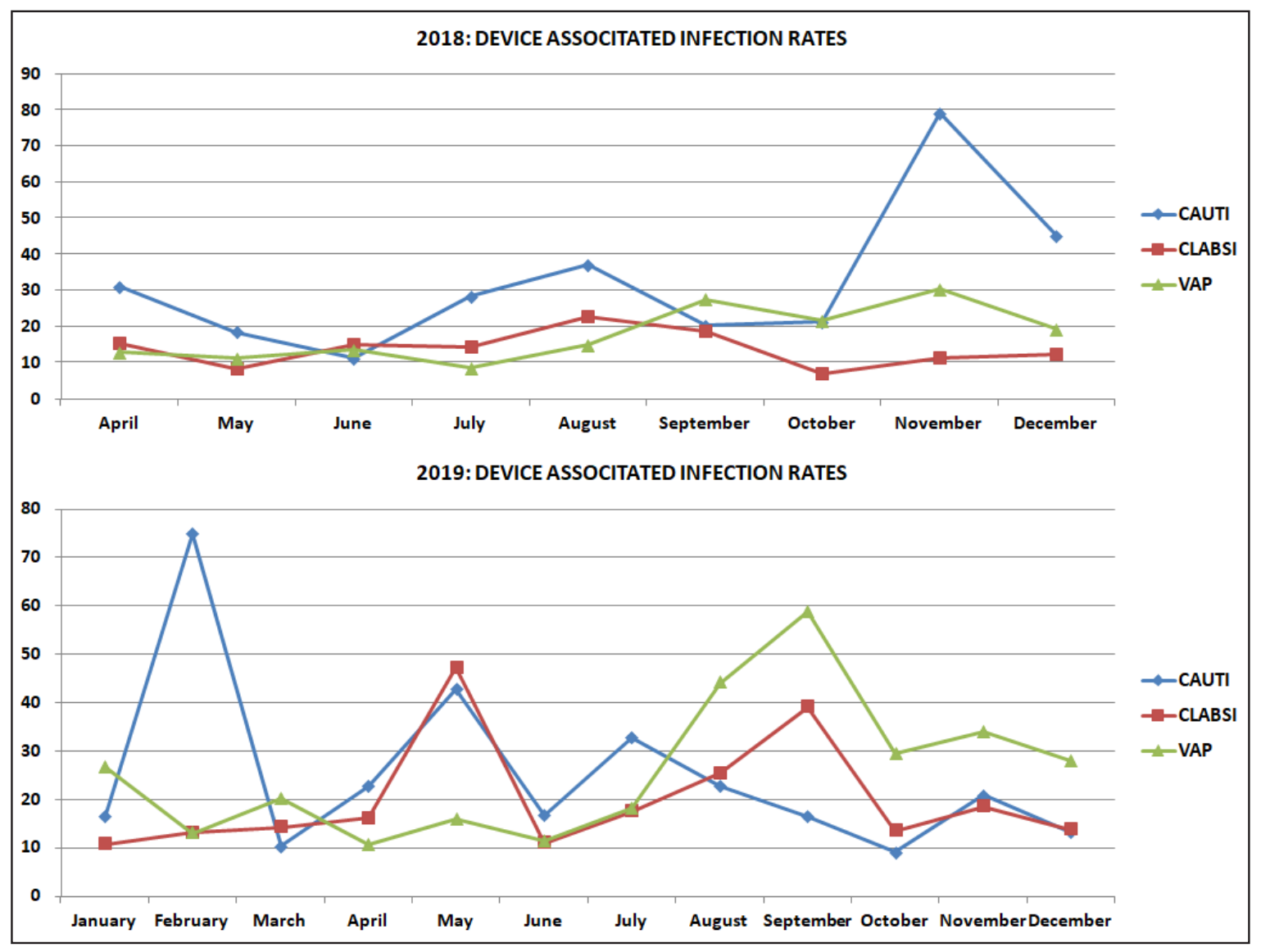

Figure 4. The Monthly Trend of DAI Rates.

1000 ventilator days VAP rate in ICUs with a ventilator utilization ratio of $0.47 .{ }^{17}$ Nevertheless, lower rates of VAP ranging from 16.92 to 17 cases per 1000 ventilator days have been reported by authors from different areas of the same state. ${ }^{14,18-20}$ Other studies from India and abroad have documented VAP rates ranging from 6.04 to 73.4 per 1000 ventilator days. ${ }^{21-28}$

The CLABSI rates as depicted by the present study's findings (17.38 per 1000 central line days) were higher than the data from other regions of the same city. ${ }^{17-20}$ Other studies from diverse geographical settings have established

Table 2. Comparison of DAI rates at the end of 2018 and 2019

\begin{tabular}{ccc}
\hline DAI rates & December & December \\
(Expressed Per 1000 Device Days) & $\mathbf{2 0 1 8}$ & $\mathbf{2 0 1 9}$ \\
\hline CAUTI & 45.45 & 13.33 \\
CLABSI & 12.34 & 13.79 \\
VAP & 19.41 & 28 \\
\hline
\end{tabular}

Table 3. Hand Hygiene Compliance Rates (September 2019December 2019)

\begin{tabular}{cc}
\hline Time Period & Hand Hygiene Compliance Rate \\
\hline September 2019 & $7.69 \%$ \\
October 2019 & $13.33 \%$ \\
November 2019 & $10.01 \%$ \\
December 2019 & $9.38 \%$ \\
\hline
\end{tabular}

a range of 3.6 to 72.56 CLABSI rates in ICU settings. ${ }^{23-29}$ In a systematic review aimed at assessing published literature on DA-HAI incidence rates between 2007 and 2017, the highest rates of CLABSI have been documented in India by Bammigatti et al from Pondicherry, India (72.56 / 1000 central line days), followed by Patil et al from Maharashtra, India (47.31/1000 central line days). ${ }^{30,31}$ The majority of the studies recording elevated CLABSI rates hailed from developing countries like India, Egypt, Mexico, and Brazil, to name a few. ${ }^{28}$ This underscores the disparity in the HIC practices in the same geographical region and the need for targeted reinforcement of intensive infection control strategies.

Similarly, the CAUTI rates showed wide variations among diverse geographical settings ranging from 1.9 to 34.2 cases per 1000 catheter days. ${ }^{28,32}$ Conceivably higher rates of CAUTI have also been illustrated in data from the developing world. ${ }^{28}$ However, compared to other Delhi studies, the CAUTI rate was higher in the present study. ${ }^{13,18-20}$ These discrepancies in DAI rates (CLABSI, CAUTI, and VAP) within the same province of a country can be partially attributed to the vast inflow of patients from the adjoining states of India due to shared borders. Additionally, the low hand hygiene compliance rates observed in the concerned setting could be fundamental to the findings of this study. Dwindling doctor: patient ratio and health care provider: patient ratio in the given hospital, in addition to the inconsistencies in staff awareness and 
training, could be the nexus of inflated DAI rates.

Interestingly, in the present study, we had observed a declining trend of CAUTI rates in Period III (Figure 4), which roughly coincided with when we started observing hand hygiene compliance in the same ICU. A substantial decrease in CAUTI rates has been observed in December 2019 (13.33/1000 catheter days) compared to December 2018 (45.45/1000 catheter days). This downtrend in CAUTI rates can be partly explained by hand hygiene surveillance activities being undertaken in the same setting. Despite a decreasing trend in DAI indices, there were no significant alterations in the other DAI indices that could be attributed to the same.

The study setting is the sole 1700 bedded tertiary care teaching institute in the eastern province, one of the city's densely populated regions. It also has boundaries in contiguity with nearby states; it caters to a substantially high number of healthcare facilities seekers. With roundthe-clock emergency services in various clinical disciplines, the hospital handles an approximate daily outpatient attendance of 6000 patients/day and 250 admissions/day. The institution continues to provide free-of-cost health care services even with an average bed occupancy rate of $104 \% .{ }^{33}$ The sheer volume of patients accessing healthcare facilities in various inpatient departments and ICUs contributes to

\section{Research Highlights}

\section{What Is Already Known?}

- The widespread availability and accessibility to critical care has inadvertently brought Hospital Acquired Infections into limelight.

- Device Associated Infections (DAIs) constitute a substantial therapeutic burden in intensive care units.

- Ventilator-Associated Pneumonia (VAP), CentralLine-Associated Blood Stream Infections (CLABSI), and Catheter Associated Urinary Tract Infection (CAUTI) constitute the major preventable HAIs.

- Multidrug-resistant organisms (MDRO) of ICU environments add to the complexity of management of DAIs.

- Surveillance and documentation of such infection control practices are essential for comparison, subsequent interventions and policy making.

\section{What Does This Study Add?}

- The study attempts to redress the paucity of literature pertaining to existing DAI rates within the institution.

- The possible impact of Hand Hygiene Surveillance by direct observation, on hand hygiene compliance as well as DAI rates, has been delved into.

- The DAI indices may be considered as benchmarks for assessing intra-institutional infection control practices and provide base-line data for future comparability. and accentuating the need for intensive infection control measures to be adopted. With the existing DAI indices observed in the present study, the number of stakeholders is high and continues to escalate with the growing patient volume. Thus, the need to revamp the existing strategies by appointing dedicated technical staff, mandatory continued training programs for healthcare providers, and bundling cannot be reemphasized enough.

\subsection{Limitations}

Though the study includes all the cases of HAIs within the specified study period, the mere presence of an observer for monitoring hand hygiene practices could at least partly boost $\mathrm{HH}$ compliance among health care workers. Thus, the $\mathrm{HH}$ compliance rates may not be reflective of actual practices. Covert observation would be ideal in such scenarios to get a clearer perspective. Also, the dearth of literature about infection control interventions and their resultant impact on HAI indices from the institute makes for a difficult comparison with previous trends.

\section{Conclusion}

With the emergence of multi-drug resistant microorganisms and the ICUs already being documented as the epicenters for MDROs, the strategic reinforcement of HIC measures has become imperative. In addition to prolonged duration of hospitalization, the excess morbidity and mortality due to multi-drug resistance further incur additional costs in inpatient care. Thus, focused HIC measures targeted at such high-risk areas warrant serious deliberation in the expected maximal impact on patient outcome. The bundle approach to curb DAI rates has been established to play a pivotal role in all HIC programs. The bundles act as a cohesive unit to ensure all steps of care are delivered and adequately documented. The "all or none" concept of bundle care approach along with bundle adherence and compliance measures are expected to reflect directly on DAI indices and patient outcome subsequently. ${ }^{34}$ Thus, the DAI indices may be considered as benchmarks for assessing intra-institutional infection control practices and provide baseline data for future comparability and strategizing measures for optimal and efficient patient management.

\section{Authors' Contributions}

BK, RJ, and RS Concept and design. BK, RJ, RS, and PP definition of intellectual content. BK, RJ, RS, and PP literature search and clinical studies. RS and PP experimental studies and data acquisition. BK and RS data \& statistical analysis. BK, RJ, RS, and PP manuscript preparation and editing.

\section{Conflict of Interest Disclosures}

The authors declare that there is no conflict of interest.

\section{Ethical Approval}

Current study was approved by University College of Medical Sciences, Delhi, India. 


\section{References}

1. Weinstein RA, Darouiche RO. Device-associated infections: a macroproblem that starts with microadherence. Clin Infect Dis. 2001;33(9):1567-1572. doi:10.1086/323130

2. Rosenthal VD, Maki DG, Graves N. The International Nosocomial Infection Control Consortium (INICC): goals and objectives, description of surveillance methods, and operational activities. Am J Infect Control. 2008;36(9):e1-12. doi:10.1016/j.ajic.2008.06.003

3. Lawes T, Lopez-Lozano JM, Nebot CA, et al. Effects of national antibiotic stewardship and infection control strategies on hospital-associated and community-associated meticillin-resistant Staphylococcus aureus infections across a region of Scotland: a non-linear time-series study. Lancet Infect Dis. 2015;15(12):1438-1449. doi:10.1016/s14733099(15)00315-1

4. Madden GR, Weinstein RA, Sifri CD. Diagnostic stewardship for healthcare-associated infections: opportunities and challenges to safely reduce test use. Infect Control Hosp Epidemiol. 2018;39(2):214-218. doi:10.1017/ice.2017.278

5. National Healthcare Safety Network (NHSN). Patient Safety Component Manual. 2020. https://www.cdc.gov/nhsn/pdfs/ pscmanual/pcsmanual_current.pdf.

6. European Centre for Disease Prevention and Control (ECDC). Incidence and Attributable Mortality of Healthcare-Associated Infections in Intensive Care Units in Europe, 2008-2012. Stockholm: ECDC; 2018.

7. Raka L. Lowbury Lecture 2008: infection control and limited resources--searching for the best solutions. J Hosp Infect. 2009;72(4):292-298. doi:10.1016/j.jhin.2009.03.017

8. Gunjiyal J, Thomas SM, Gupta AK, et al. Device-associated and multidrug-resistant infections in critically ill trauma patients: towards development of automated surveillance in developing countries. J Hosp Infect. 2011;77(2):176-177. doi:10.1016/j.jhin.2010.09.019

9. Haley RW, Culver DH, White JW, Morgan WM, Emori TG. The nationwide nosocomial infection rate. A new need for vital statistics. Am J Epidemiol. 1985;121(2):159-167. doi:10.1093/oxfordjournals.aje.a113988

10. Dumpis U, Balode A, Vigante D, et al. Prevalence of nosocomial infections in two Latvian hospitals. Euro Surveill. 2003;8(3):73-78. doi:10.2807/esm.08.03.00405-en

11. McFee RB. Nosocomial or hospital-acquired infections: an overview. Dis Mon. 2009;55(7):422-438. doi:10.1016/j. disamonth.2009.03.014

12. Haley RW, Culver DH, White JW, et al. The efficacy of infection surveillance and control programs in preventing nosocomial infections in US hospitals. Am J Epidemiol. 1985;121(2):182-205. doi:10.1093/oxfordjournals.aje. a113990

13. Kashyap B, Gupta S, Sarin Y. Device-associated infection rates with microbiological profile and antibiogram pattern from an adult medical-surgical ICU of a tertiary care hospital. Int J Infect Dis. 2016;45 Suppl 1:300. doi:10.1016/j. ijid.2016.02.661

14. Kashyap B, Gupta S, Goyal N, Sarin Y. Device-associated infection rates with microbiological profile and antibiogram pattern from an adult medical-surgical intensive care unit of a tertiary care hospital. Indian Journal of Medical Specialities. 2017;8(1):25-30. doi:10.1016/j.injms.2016.12.001

15. Singh S, Pandya Y, Patel R, Paliwal M, Wilson A, Trivedi S. Surveillance of device-associated infections at a teaching hospital in rural Gujarat--India. Indian J Med Microbiol. 2010;28(4):342-347. doi:10.4103/0255-0857.71830

16. Salomao R, Rosenthal VD, Grimberg G, et al. Deviceassociated infection rates in intensive care units of Brazilian hospitals: findings of the International Nosocomial Infection Control Consortium. Rev Panam Salud Publica. 2008;24(3):195-202. doi:10.1590/s1020-49892008000900006

17. Afhami S, Seifi A, Hajiabdolbaghi M, et al. Assessment of device-associated infection rates in teaching hospitals in Islamic Republic of Iran. East Mediterr Health J. 2019;25(2):90-97. doi:10.26719/emhj.18.015

18. Khan ID, Basu A, Kiran S, Trivedi S, Pandit P, Chattoraj A. Device-Associated Healthcare-Associated Infections (DAHAI) and the caveat of multiresistance in a multidisciplinary intensive care unit. Med J Armed Forces India. 2017;73(3):222231. doi:10.1016/j.mjafi.2016.10.008

19. Kumar S, Sen P, Gaind R, et al. Prospective surveillance of device-associated health care-associated infection in an intensive care unit of a tertiary care hospital in New Delhi, India. Am J Infect Control. 2018;46(2):202-206. doi:10.1016/j. ajic.2017.08.037

20. Mathur P, Tak V, Gunjiyal J, et al. Device-associated infections at a level-1 trauma centre of a developing nation: impact of automated surveillance, training and feedbacks. Indian J Med Microbiol. 2015;33(1):51-62. doi:10.4103/02550857.148378

21. Empaire GD, Guzman Siritt ME, Rosenthal VD, et al. Multicenter prospective study on device-associated infection rates and bacterial resistance in intensive care units of Venezuela: International Nosocomial Infection Control Consortium (INICC) findings. Int Health. 2017;9(1):44-49. doi:10.1093/inthealth/ihw049

22. Mehta A, Rosenthal VD, Mehta Y, et al. Device-associated nosocomial infection rates in intensive care units of seven Indian cities. Findings of the International Nosocomial Infection Control Consortium (INICC). J Hosp Infect. 2007;67(2):168-174. doi:10.1016/j.jhin.2007.07.008

23. Kübler A, Duszynska W, Rosenthal VD, et al. Deviceassociated infection rates and extra length of stay in an intensive care unit of a university hospital in Wroclaw, Poland: International Nosocomial Infection Control Consortium's (INICC) findings. J Crit Care. 2012;27(1):105. e5-105.e10. doi:10.1016/j.jcrc.2011.05.018

24. Apostolopoulou E, Raftopoulos V, Filntisis G, et al. Surveillance of device-associated infection rates and mortality in 3 Greek intensive care units. Am J Crit Care. 2013;22(3):e12-20. doi:10.4037/ajcc2013324

25. Datta P, Rani H, Chauhan R, Gombar S, Chander J. Healthcare-associated infections: risk factors and epidemiology from an intensive care unit in Northern India. Indian $J$ Anaesth. 2014;58(1):30-35. doi:10.4103/0019-5049.126785

26. Inan A, Ozgultekin A, Akcay SS, et al. Alterations in bacterial spectrum and increasing resistance rates in isolated microorganisms from device-associated infections in an intensive care unit of a teaching hospital in Istanbul (20042010). Jpn J Infect Dis. 2012;65(2):146-151.

27. Guanche-Garcell H, Requejo-Pino O, Rosenthal VD, Morales-Pérez C, Delgado-González O, FernándezGonzález D. Device-associated infection rates in adult intensive care units of Cuban university hospitals: International Nosocomial Infection Control Consortium (INICC) findings. Int J Infect Dis. 2011;15(5):e357-362. 
doi:10.1016/j.ijid.2011.02.001

28. Pettemerides $\mathrm{Y}$, Vasilios R. Incidence rate of deviceassociated, hospital acquired infections in ICUs: a systematic review developed versus developing economies. Int J Caring Sci. 2018;11(3):1913-1941.

29. Salomao R, Rosenthal VD, Grimberg G, et al. Deviceassociated infection rates in intensive care units of Brazilian hospitals: findings of the International Nosocomial Infection Control Consortium. Rev Panam Salud Publica. 2008;24(3):195-202. doi:10.1590/s1020-49892008000900006

30. Bammigatti C, Doradla S, Belgode HN, Kumar $H$, Swaminathan RP. Healthcare associated infections in a resource limited setting. J Clin Diagn Res. 2017;11(1):OC01OC04. doi:10.7860/jcdr/2017/23076.9150

31. Patil HV, Patil VC, Ramteerthkar MN, Kulkarni RD. Central venous catheter-related bloodstream infections in the intensive care unit. Indian J Crit Care Med. 2011;15(4):213223. doi:10.4103/0972-5229.92074

32. Talaat M, El-Shokry M, El-Kholy J, et al. National surveillance of health care-associated infections in Egypt: developing a sustainable program in a resource-limited country. Am J Infect Control. 2016;44(11):1296-1301. doi:10.1016/j. ajic.2016.04.212

33. Guru Tegh Bahadur Hospital. General information. 2019, October 13. http://health.delhigovt.nic.in/wps/wcm/ connect/doit_gtbh/GTBH/Home/General+Information.

34. Cooke FJ, Holmes AH. The missing care bundle: antibiotic prescribing in hospitals. Int J Antimicrob Agents. 2007;30(1):25-29. doi:10.1016/j.ijantimicag.2007.03.003 